\title{
Effect of a new respiratory care bundle on bronchopulmonary dysplasia in preterm neonates
}

\author{
Cristina Ramos-Navarro ${ }^{1}$ (D) Noelia González-Pacheco ${ }^{1}$ - Ana Rodríguez-Sánchez de la Blanca ${ }^{1}$. \\ Manuel Sánchez-Luna ${ }^{1}$
}

Received: 25 February 2020 / Revised: 15 May 2020 / Accepted: 16 May 2020 / Published online: 2 June 2020

(C) Springer-Verlag GmbH Germany, part of Springer Nature 2020

\begin{abstract}
The development of devices that can fix the tidal volume in high-frequency oscillatory ventilation (HFOV) has allowed for a significant improvement in the management of HFOV. At our institution, this had led to the earlier use of HFOV and promoted a change in the treatment strategy involving the use of higher frequencies (above $15 \mathrm{~Hz}$ ) and lower high-frequency tidal volumes (VThf). The purpose of this observational study was to assess how survival without bronchopulmonary dysplasia grades 2 and 3 (SF-BPD) is influenced by these modifications in the respiratory strategy applied to preterm infants (gestational age $<32$ weeks at birth) who required mechanical ventilation (MV) in the first 3 days of life. We compared a baseline period (2012-2013) against a period in which this strategy had been fully implemented (2016-2017). A total of 182 patients were exposed to MV in the first 3 days of life being a higher proportion on HFOV at day 3 in the second period 79.5\% ( $n$ 35) in 2016-2017 vs 55.4\% ( $n$ 31) in 2012-2013. After adjusting for perinatal risk factors, the second period is associated with an increased rate of SF-BPD (OR 2.28; CI 95\% 1.072-4.878); this effect is more evident in neonates born at a gestational age of less than 29 weeks (OR 4.87; 95\% CI $1.9-12.48)$.

Conclusions : The early use of HFOV combined with the use of higher frequencies and very low VT was associated with an increase in the study population's SF-BPD.
\end{abstract}

What is Known:

- High-frequency ventilation with volume guarantee improve ventilation stability and has been shown to reduce lung damage in animal models.

What is New:

- The strategy of an earlier use of high-frequency oscillatory ventilation combined with the use of higher frequencies and lower tidal volume is associated to an increase in survival without bronchopulmonary dysplasia in our population of preterm infants.

Keywords High-frequency ventilation $\cdot$ Lung protection $\cdot$ Bronchopulmonary dysplasia $\cdot$ Ventilatory-induced lung injury $\cdot$ Target tidal volume $\cdot$ Preterm infants

\begin{tabular}{lll} 
& \multicolumn{2}{l}{ Abbreviations } \\
& $\Delta \mathrm{Phf}$ & Delta pressure \\
\cline { 1 - 3 } Communicated by Daniele De Luca & BPD & Bronchopulmonary dysplasia type 2-3 \\
\hline $\begin{array}{l}\text { Cristina Ramos-Navarro } \\
\text { cramosn@salud.madrid.org }\end{array}$ & BW & Birth weight \\
& CMV & Conventional mechanical ventilation \\
Noelia González-Pacheco & CRIB & Critical index for babies \\
noelia.gonzalez.pacheco@gmail.com & DOL & Days of life \\
Ana Rodríguez-Sánchez de la Blanca & GA & Gestational age \\
nucka83@hotmail.com & HFOV & High-frequency oscillatory ventilation \\
Manuel Sánchez-Luna & Hz & Hertz \\
msluna@ salud.madrid.org & INSURE & Intubation-surfactant administration-extubation \\
& LISA & Less-invasive surfactant administration \\
Neonatology Department, Gregorio Marañón University Hospital, & MV & Mechanical ventilation \\
O’Donnell 48, 28009 Madrid, Spain & NEC & Nasal continuous airway pressure
\end{tabular}


PDA Patent ductus arterioso

PSV Pressure support ventilation

RDS Respiratory distress syndrome

SF-BPD Survival without bronchopulmonary dysplasia

SF-PCU Survival free pathological cranial ultrasound

SNIPPV Synchronized nasal ventilation

VG Volume guarantee

VT Tidal volume

VThf High-frequency tidal volume

\section{Introduction}

Premature infants, due to their immaturity and lack of pulmonary surfactant, often develop neonatal respiratory distress syndrome (RDS) and require the implementation of respiratory support measures to maintain adequate gas exchange [1]. On the other hand, these patients are particularly susceptible to lung injury caused by mechanical ventilation (MV), a key factor in the development of bronchopulmonary dysplasia (BPD), which has important consequences on long-term lung function [2-4]. According to animal models, the main mechanism of ventilator-induced lung injury (VILI) is pulmonary overdistension due to the use of excessively high tidal volumes (VT). Barotrauma, atelectrauma, and biotrauma are also very important factors [5-7].

Measures to reduce the level of VILI include avoiding MV, for example, through the prophylactic use of noninvasive respiratory support with nasal continuous positive airway pressure (nCPAP) or noninvasive nasal ventilation and the early administration of intratracheal exogenous surfactant, or ventilatory strategies to mitigate lung injury in those patients who require intubation and $\mathrm{MV}$ [8]. In this latter group of patients, the main therapeutic goal is to promote adequate homogeneous alveolar recruitment, thus avoiding alveolar overdistension by using lower VT and minimizing exposure to high oxygen concentrations.

High-frequency oscillatory ventilation (HFOV) uses very small high-frequency tidal volumes (VThf), less than that of the anatomic dead space, at a supraphysiological frequency $(>$ 180 cycles/min). Lung recruitment maneuvers are designed to achieve a mean airway pressure that maintains the lung inflated without overdistension. This limits lung injury related to alveolar overdistension due to a large VT, as well as any damage induced by constant airway collapse and reopening. So, this technique represents a very promising strategy to reduce VILI. However, despite the good results initially reported in animal models [9], in premature patients, it has not led to a clinical uniform reduction in the incidence of BPD compared with conventional mechanical ventilation (CMV) when used electively in very immature infants [10].
One possible explanation is that initial animal experiments with HFOV were all performed at high frequencies $[11,12]$, but then lower frequencies were used in a clinical context, probably because physicians had reservations about using high oscillatory pressure amplitudes. When using HFOV, VThf depends on the oscillation amplitude and inspiratory time being inversely proportional to the oscillation frequency [13] and the lung and tubbing conditions. In classic high-frequency ventilators, in which VThf cannot be fixed, an increase in the frequency leads to a decrease in VThf, if the pressure amplitude $(\Delta \mathrm{Phf})$ remains the same, and therefore a decrease in ventilation $[11,12,14$, 15]. The value of $\Delta \mathrm{Phf}$ has to be increased at higher frequencies in order to maintain a constant VThf. Hence, relatively low frequencies were used [9], especially in studies using the Dräger Babylog® 8000 ventilator whose manufacturer recommends frequencies of around 10 hertz (Hz) [16]. Furthermore, as VThf cannot be fixed, it varies according to changes in lung mechanics.

The appearance of volume guarantee (VG) mode, when combined with HFOV, allows VThf and the frequency to be adjusted independently, and VThf can be kept constant.

These points were confirmed in early studies of HFOV+ VG in neonatal animal models [17]. In HFOV+VG mode (Babylog® VN500, Dräger, Lübeck, Germany), ventilators achieve VThf stability by automatically adjusting $\Delta \mathrm{Phf}[18]$. VThf fluctuates in the short term, but remains very close to the target value over longer periods [19]. The increase in $\Delta \mathrm{Phf}$ necessary to maintain a constant VThf measured in the airway opening is damped as it traverses the airways to the alveoli, especially at higher frequencies [20-22], until it falls to a minimum at the resonant frequency, as described in several studies [21, 23-26]. This optimal frequency, which results in adequate gas transport during HFOV and the least harmful pressures, depends on underlying lung condition wherein higher frequencies are better suited to pulmonary diseases with low compliance and short time constants such as RDS in preterm infants [19, 21].

Following the results of previous studies, we have gone back to the initial concept of HFOV management, by using very high frequencies, even higher than those used classically (10-15 Hz), with the aim of applying the lowest VThf possible while maintaining adequate ventilation [27, 28].

Recently, in an animal model, this strategy of very high frequencies $(20 \mathrm{~Hz})$ and lower VThf has been shown to reduce histological lung injury compared with CMV and HFOV at standard frequencies $(10 \mathrm{~Hz})[29]$.

After demonstrating the clinical feasibility of this strategy in preterm infants [30], we implemented this approach at our institution for premature patients who required intubation and invasive mechanical ventilation (MV).

Noninvasive management strategies have also been enhanced with the use of synchronized noninvasive mechanical 
ventilation (SNIMV) as a rescue treatment in the event of nCPAP failure [31] and less-invasive surfactant administration (LISA) techniques in spontaneously breathing preterm infants [32], but neither of these strategies has been shown to clearly reduce the incidence of BPD [33-35].

Objectives To assess how mortality and the incidence of type 2-3 bronchopulmonary dysplasia in preterm infants (gestational age $<32$ weeks at birth) exposed to mechanical ventilation (MV) during the first 3 days of life are affected by our modification to respiratory management strategy: the earlier implementation of HFOV with higher frequencies and a lower tidal volume.

\section{Materials and methods}

Prospective, observational, single-center study was carried out in the Neonatal Department of the Hospital Gregorio Marañón in Madrid.

Inclusion criteria Preterm infants born at a gestational age of less than $32+0$ weeks admitted to the neonatal intensive care unit (NICU) between January 2012 and December 2017 and who had been exposed to invasive MV (for more than $1 \mathrm{~h}$ ) in the first 3 days of life.

Exclusion criteria Referred patients who were more than $6 \mathrm{~h}$ old at admission, patients in whom active resuscitation measures were not initiated, and patients with congenital malformations.

\section{Changes to the ventilator management strategy (Appendix link)}

During the baseline period (2012-2013), our hospital used a Babylog® 8000 (Dräger, Lübeck, Germany) ventilator which provides HFOV without VG. These ventilators can measure but cannot fix the high-frequency tidal volume (VThf). Although we began using HFOV+VG (Babylog® VN500, Dräger, Lübeck, Germany) in 2014, the strategy was not implemented for all premature infants until 2016.

- An earlier rescue therapy with HFOV was implemented in the second period (2016-2017) with lower transition criteria (online appendix).

- The acquisition of HFOV with volume guarantee permitted the modification of the respiratory strategy in the second period, applying the maximum frequency that allows a minimum VThf while maintaining $\mathrm{DCO}_{2}$ constant (online appendix).
After the transition to HFOV, a regulated recruitment maneuver was carried out in the two periods by an oxygenationguided stepwise increase in mean airway pressure (PMAP) to determine the opening pressure, then a stepwise decrease in PMAP to identify the closing pressure. After reopening the lung, final PMAP is defined as the closing pressure +2 $\mathrm{cmH}_{2} \mathrm{O}[30]$.

The same CMV management protocol was used throughout the study, that is, pressure support ventilation combined with VG (4-5 mL/kg). A Drager Babylog 8000 plus ventilator was used in the baseline period and a Babylog® VN500 in the second period with the new management strategy.

The same surfactant (Beractant) and surfactant administration or intubation criteria were used in both periods, although synchronized nasal intermittent positivepressure ventilation (SNIPPV) was implemented in the second period as a rescue strategy to avoid intubation if nasal continuous positive airway pressure (nCPAP) failed. We also modified the surfactant administration technique. In the second period, it was administered through a tracheal catheter to spontaneously breathing patients (less-invasive surfactant administration, LISA), while in the first period, it was administered after intubation and connection to MV, followed by early extubation (within $1 \mathrm{~h}$ ), in what is known as the INSURE method-INtubation-SURfactant-Extubation.

As only patients who required intubation and connection to mechanical ventilation for more than $1 \mathrm{~h}$ in the first 3 days postpartum were included in the study, changes in noninvasive management did not have a significant effect on the study objectives. Furthermore, these changes would probably apply to more severe cases of respiratory distress syndrome in the second period as they correspond to patients who did not respond to noninvasive strategies. For a better understanding of the impact of changes to noninvasive respiratory management on the main outcome, we also analyzed the group of infants exposed to MV after the first 3 days of life and those who did not require MV during hospitalization.

Variables We collected the following perinatal variables with respect to mortality and the development of BPD: gender; gestational age at birth (GA); birth weight; antenatal steroid treatment (a complete course was defined as the administration of two doses, the last one at least $4 \mathrm{~h}$ before delivery) and the results of placental pathology (classification elaborated by Redline) [36, 37]; respiratory support at birth and during hospitalization; clinical risk index for babies (CRIB) score as a predictor of mortality [38]; time on MV (hours); air leak, including pneumothorax or pulmonary interstitial emphysema; and any abnormalities detected in cranial ultrasound (intracranial hemorrhage grade $\geq 3$ or periventricular leukomalacia). Mortality was considered at discharge. 
Target variable Survival without bronchopulmonary dysplasia grades 2 and 3 (moderate-severe) (SF-BPD). Bronchopulmonary dysplasia (BPD) was defined as moderate or severe using the criteria reported by Jobe and Bancalari at a postmenstrual age of 36 weeks [39], adding physiologic definition [40].

Variables were evaluated for the whole study population as well as for the group of infants born at a gestational age of less than $29+0$ weeks.

\section{Statistical analysis}

Categorical data are expressed as frequencies and percentages, and continuous data as medians and interquartile range (25th75th percentile). The chi-squared test or Fisher's exact test was used to compare categorical variables and Student's $t$ test, the Mann-Whitney $U$ test or the Wilcoxon rank-sum test for continuous variables according to the normal or nonnormal distribution of data. Binary logistic regression was used to analyze the primary outcome. Crude and adjusted odds ratios (OR) were calculated with a $95 \%$ confidence interval. Confounders were included according to clinical relevancy; so, the maximal model comprises gender [41], gestational age [42], antenatal steroids [43], and placental histology [44]. CRIB scores were not included as they could be affected by the different respiratory management strategies employed and also to avoid collinearity with gestational age. We use a stepwise-background regression model. The final models were internally validated by comparing the estimation coefficients. Statistical significance was set at $p<0.05$. Statistical analyses were performed using the Statistical Package for the Social Sciences (SPSS $®$ version 21.0) program (IBM, Armonk, New York, USA).

\section{Results}

A total of 182 patients subjected to MV in the first 3 days of life were included in the study out of the 618 patients born between January 2012 and December 2017 (Fig. 1). The subjects had an average gestational age of 27.1 weeks (IQR 25.228.8), and the mean weight was $956 \mathrm{~g}$ (IQR 707.5-1150).

When considering all the preterm infants born at less than 32 weeks' GA in both periods $(n=428)$, a lower proportion of patients required $\mathrm{MV}$ in the first 3 days postpartum in the second period (Table 1). Thus, after adjusting for prenatal risk factors, the second period was associated with a decreased probability of being exposed to MV in the first 3 days of life (OR 0.540; 95\% CI 0.343-0.852; $p=0.008$ ).

Patients exposed to more than $1 \mathrm{~h}$ of mechanical ventilation in the second period (2016-2017) were significantly more immature and, according to the CRIB score, had an increased risk of mortality compared with patients in the baseline period (2012-2013). There were no significant differences in gender, prenatal corticosteroid course completion percentages, or placental pathology (Table 2).
Fig. 1 Flow Chart. A total of 618 preterm infants born with less than 32 weeks of GA were admitted in the NICU between January 2012 and December 2017. Period 2012-2013 is compared with 2016-2017

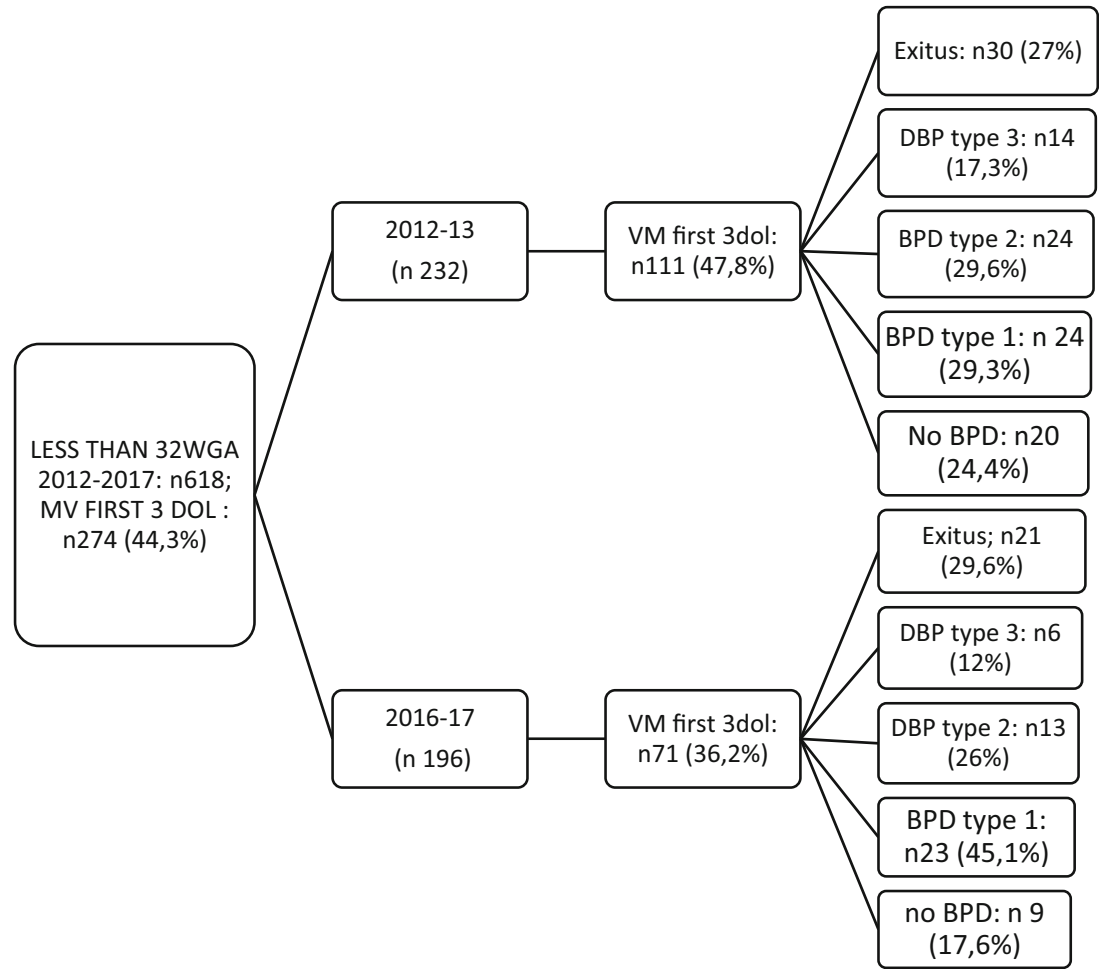


Table 1 Distribution of respiratory management variables according to the study periods in the whole population of preterm infants (born with less than 32 weeks GA). INSURE, intubation-surfactant administrationextubation; LISA, less-invasive surfactant administration (surfactant without intubation); Intubated, mechanical ventilation exposure more than 1 h; VMNIs, synchronized nasal ventilation; $M V$, mechanical ventilation; dol, days of life; $H F O V$, high-frequency oscillatory ventilation; $S F-B P D$, survival without bronchopulmonary dysplasia type $2-3 ; B P D 2-3$, bronchopulmonary dysplasia type 2-3. Data expressed as frequencies and percentages in parenthesis

\begin{tabular}{llll}
\hline & $2012-2013(n$ 232) & 2016-2017(n 196) & $p$ value \\
\hline Intubation in delivery room & $71(30.6 \%)$ & $55(28.1 \%)$ & 0.059 \\
Surfactant administration & $129(55.6 \%)$ & $93(47.4 \%)$ & 0.093 \\
- INSURE & $30(23.3 \%)$ & $0(0 \%)$ & $39(41.9 \%)$ \\
- LISA & $4(3.1 \%)$ & $54(58.1 \%)$ & $45(22.9 \%)$ \\
• Intubated for more than 1 hour & $95(73.6 \%)$ & $71(36.2 \%)$ & 0.001 \\
SNIPPV during hospitalization; & $12(5.2 \%)$ & $35(79.5 \%)$ & 0.018 \\
MV exposure in the first 3 dol & $111(47.8 \%)$ & $144(73.5 \%)$ & 0.019 \\
$\bullet$ HFOV at 3 dol & $31(56.4 \%)$ & $26(13.3 \%)$ & 0.013 \\
SF-BPD & $144(62.1 \%)$ & $26(15.3 \%)$ & 0.888 \\
Mortality & $33(14.2 \%)$ & & 0.005 \\
BPD 2-3 & $55(27.6 \%)$ &
\end{tabular}

The percentage of patients treated with HFOV on the third day postpartum was greater in the second period $(56.4 \%$ in $2012-2013$ vs $79.5 \%$ in $2016-2017 ; p=0.019)$. HFOV was initiated at an earlier age, with an increased frequency and significantly lower VThf. There were no differences in the other parameters (Table 3 ).

There were no significant differences in the incidence of pneumothorax/interstitial emphysema or the MV exposure time during the first 3 days postpartum; however, time of exposure to $\mathrm{MV}$ over the entire hospital admission period was greater in the second period (Table 2). There were no differences in mortality rates between the two periods.

After adjusting for perinatal risk factors, the second period was associated with a significant increase in survival without BPD type 2-3 (SF-BPD) not only in the whole population of preterm infants but also when considered those patients exposed to mechanical ventilation in the first 3 days of life (Table 4). This outcome was even more marked in the group of patients with a gestational age of less than 29 weeks, where the incidence of BPD was reduced by at least $44 \%$ in the
Table 2 Distribution of perinatal variables and outcomes according to study periods considering only patients exposed to mechanical ventilation during the first 3 days after birth. Data expressed frequencies and percentages in parenthesis or median and interquartile range $(25$ th -75 th percentile). $G A$, gestational age; $d o l$, days of life; $C R I B$, critical index for babies; $M V$, mechanical ventilation; $P D A$, patent ductus arteriosus

\begin{tabular}{|c|c|c|c|}
\hline Perinatal variables & $2012-2013(n$ 111) & 2016-2017 (n 71) & $p$ value \\
\hline GA (weeks) & $27.43(25.2-29.2)$ & $26.72(24.5-28.1)$ & 0.046 \\
\hline Weight $(g)$ & $1019.4(750-1240)$ & $949.8(700-1140)$ & 0.156 \\
\hline Male & $71(64 \%)$ & $49(69 \%)$ & 0.524 \\
\hline Antenatal steroids (complete course) & $53(47.7 \%)$ & $35(49.3 \%)$ & 0.88 \\
\hline Pathological placental histology & $61(55 \%)$ & $36(50.7 \%)$ & 0.648 \\
\hline - Choriamnionitis & $34(30.6 \%)$ & $20(28.2 \%)$ & 0.739 \\
\hline - Vascular pathology & $27(24.3 \%)$ & $16(22.5 \%)$ & 0.859 \\
\hline Postnatal variables & $2012-2013(n$ 111) & 2016-2017 ( $n$ 71) & $p$ value \\
\hline CRIB Index & $4.7(2-8)$ & $6.7(2-10)$ & 0.004 \\
\hline MV first 3 dol (hs) & $40.7(12-72)$ & $46.9(24-72)$ & 0.120 \\
\hline MV after 3 dol (hs) & $335.1(0-390)$ & $359.6(2-552)$ & 0.069 \\
\hline MV during hospitalization (days) & $15.6(1.9-18.1)$ & $17.4(2.3-27.2)$ & 0.045 \\
\hline Pneumothorax & $19(17.1 \%)$ & $12(16.9 \%)$ & 1 \\
\hline PDA & $55(49.5 \%)$ & $43(60.6 \%)$ & 0.171 \\
\hline Nosocomial sepsis & $71(64 \%)$ & $43(60.6 \%)$ & 0.754 \\
\hline
\end{tabular}


Table 3 Comparison of management and settings on HFOV between periods in patients supported with HFOV on day 3 after birth. Data expressed as mean (IQR). PMAP, mean airway pressure; VThf, high- frequency tidal volume; $D C O 2$, carbon dioxide diffusion coefficient; $\mathrm{FiO}$, fraction of inspired oxygen; $\mathrm{HFOV}$, high-frequency oscillatory ventilation; $C M V$, conventional mechanical ventilation

\begin{tabular}{llll}
\hline HFOV & $2012-2013(n$ 31) & $2016-2017 n(35)$ & $p$ value \\
\hline Age at VAFO (hs) & $22.21(15.45-28.95)$ & $12.8(6.7-18.8)$ & 0.006 \\
Recruit MAP $(\mathrm{cmH} 2 \mathrm{O})$ & $12.9(12.03-13.83)$ & $12.8(11.99-13.62)$ & 0.728 \\
Frequency, $\max (\mathrm{Hz})$ & $9.26(8.76-9.75)$ & $15.06(14.33-15.78)$ & $<0.001$ \\
VTHf $\left(\mathrm{mL} \mathrm{kg}^{-1}\right)$ & $2.29(2.04-2.53)$ & $1.67(1.57-1.78)$ & $<0.001$ \\
DCO2 $\left(\mathrm{mL}^{2} \mathrm{~s}^{-1}\right)$ & $38.32(26.8-49.84)$ & $36.82(26.45-47.12)$ & 0.772 \\
FiO2 $(\mathrm{max})$ & $65.45(54.29-76.6)$ & $36.92(49.46-64.36)$ & 0.490 \\
Time on HFOV (hs) & $282.38(178.35-386.42)$ & $300.82(206.35-395.3)$ & 0.693 \\
Time on CMV (hs) & $495.01(183.96-806.03)$ & $308.02(135.41-480.65)$ & 0.189 \\
\hline
\end{tabular}

second period (Tables 5 and 6). Also, with regard to patients treated using HFOV in the third day postpartum, SF-BPD increased by at least $48 \%$ in the second period (Table 6 ).

There were no differences in SF-BPD rates between the two periods in infants exposed to MV after the 3 days postpartum (45.2\% 2012-2013 and 52.2\% 2016-2017; $p=0.784$; OR $1.32 ; 95 \%$ CI $0.449-3.907)$ or infants with no exposure to MV during hospitalization (96.7\% 2012-2013 and 99\% 2016-2017; $p=0.342$; OR 3.487; 95\% CI 0.356-34.09). (Tables 4 and 6).

\section{Discussion}

Changes implemented in respiratory management strategies for preterm infants have led to a reduction in intubation rates and an increase in survival without bronchopulmonary dysplasia grades 2 and 3 (SF-BPD) across the entire population of preterm infants. This effect is mainly at the expense of the group of infants exposed to mechanical ventilation in the first 3 days of life, associated with the modifications implemented in the mechanical ventilation strategy during the second period. We did not observe any significant differences in mortality, with this effect being attributed to a decrease of at least $10 \%$ in the incidence of BPD 2-3 in the second period.

The use of HFOV as an early rescue strategy was evident in this population, with a significantly higher proportion of patients receiving HFOV on day 3 postpartum in the second period, reaching almost $80 \%$ (Table 1). Along with an earlier age at the beginning of HFOV treatment, we significantly reduced administered tidal volume among patients treated with the new strategy by using higher frequencies and keeping the other parameters constant $\left(\mathrm{DCO}_{2}, \mathrm{PMA}\right.$, and $\mathrm{FiO}_{2}$ level) (Table 3).

There is not enough data on the best tidal volume to be delivered during HFOV, or even for conventional ventilation, and it may differ between patients and depending on the course of the disease $[45,46]$. As such, the tidal volume
Table 4 Results of adjusted binary logistic regression analysis for main outcomes in the second study period (2016-2017) as compared with the first study period (2012-2013). Adjusted for perinatal risk factors: gestational age, gender, antenatal steroids, and placental histology. $S F$ -
$B P D$ 2-3, survival without BPD grades 2-3; $M V$, mechanical ventilation; $H F O V$, high-frequency oscillatory ventilation; $S F$, survival without; $d o l$, days of life

\begin{tabular}{llc}
\hline 2016-2017 vs 2012-2013* & OR & 95\% IC value \\
\hline SF-BPD (all preterm infants) & 2.415 & $1.409-4.138$ \\
SF-BPD in patients exposed to MV in the first 3 dol. & 2.286 & $1.072-4.878$ \\
SF-BPD in patients in HFOV at 3 dol & 4.074 & $1.054-15.735$ \\
SF-BPD in infants exposed to MV after the first 3 dol. & 1.327 & $0.449-2.907$ \\
SF-BPD in infants not exposed to MV during hospitalization & 3.487 & $0.356-34.09$ \\
SF-pathologic cranial ultrasound (all preterm infants) & 0.855 & $0.510-1.431$ \\
SF-pathologic cranial ultrasound in patients exposed to MV in the first 3 dol & 0.629 & $0.324-1.223$ \\
DBP 2-3 in survivors (all preterm infants) & 0.323 & $0.173-0.606$ \\
DBP 2-3 in survivors exposed to MV in the first 3dol & 0.380 & $0.161-0.898$ \\
\hline
\end{tabular}


Table 5 Distribution of main outcome variables according to study periods in the group of infants born with less than 29 wGA exposed to mechanical ventilation during the first 3 days after birth. Data expressed in frequencies and percentages are in parenthesis. $B P D$, bronchopulmonary dysplasia; $S F-B P D$, survival without bronchopulmonary dysplasia type $2-3 ; S F-P C U$, survival without pathological cranial ultrasound

\begin{tabular}{llll}
\hline Less than 29 wGA & $2012-2013(n 81)$ & $2016-2017(n$ 58) & $p$ value \\
\hline Mortality & $28(34.6 \%)$ & $19(32.8 \%)$ & 0.857 \\
BPD type 2* & $20(37.7 \%)$ & $11(28.2 \%)$ & 0.102 \\
BPD type 3* & $14(26.4 \%)$ & $4(10.3 \%)$ & 0.066 \\
SF-BPD & $19(23.5 \%)$ & $24(41.4 \%)$ & 0.027 \\
SF-BPD (HFOV at 3 dol) $(n$ 59) & $3 / 28(10.7 \%)$ & $11 / 31(35.5 \%)$ & 0.034 \\
SF-pathological cranial ultrasound & $42(51.9 \%)$ & $25(43.1 \%)$ & 0.390 \\
\hline
\end{tabular}

* In survivors

should be adjusted individually in each patient, while also taking into account that its value may differ according to each ventilator's measurement method. The Babylog® VN500 generates a sinusoidal pressure signal around a set mean airway pressure and features both active inspiration and active expiration. The VG mode is volume-targeted ventilation where the microprocessor compares the VThf for the previous breath, using leak-compensated VThf, and adjusts delta pressure to achieve the set VThf.

Minimizing the tidal volume by increasing the frequency is a safe, feasible strategy that seems to reduce ventilatorinduced lung injury. In animal models, ventilation using high frequencies $(20 \mathrm{~Hz})$ and a low VT $(1.56 \mathrm{~mL} / \mathrm{kg})$ decreased histological lung damage in comparison with both CMV (VT $7.33 \pm 0.20 \mathrm{~mL} / \mathrm{kg}$ ) and HFOV at lower frequencies (10 Hz; VT $2.54 \mathrm{~mL} / \mathrm{kg})$ [21].

This concept has also been evaluated recently in preterm infants by Zannin et al. using increasing frequencies while applying higher oscillatory amplitudes to maintain a constant $\mathrm{DCO}_{2}$ [47]. In this study, VThf was measured and found to take lower values at higher frequencies. The use of the highest frequency that maintains adequate ventilation in patients with diffuse alveolar damage has been proposed as the optimal approach following correct lung recruitment [21, 48, 49]. Even when higher delta pressures ( $\Delta \mathrm{Phf})$ are administered at the airway opening, this pressure is increasingly dampened along the endotracheal tube at higher frequencies, so it is minimal in the distal airway.

The incorporation of VG on HFOV results in lower VThf fluctuations with greater ventilation stability [17], which implies a further improvement obtained through this strategy.

The use of VG on HFOV at standard frequencies $(7-12 \mathrm{~Hz})$ has also been extended to other neonatal units, yielding less fluctuation in oxygen saturation and $\mathrm{PCO}_{2}$ levels $[19,50-52]$.

In the present study, the combination of the earlier use of HFOV with a strategy involving higher frequencies and a lower tidal volume was associated with a reduction in bronchopulmonary dysplasia. This effect was particularly evident in patients with a gestational age of less than 29 weeks, probably because they are at an earlier stage of pulmonary development in which preventing ventilatorinduced lung injury plays a key role in reducing the incidence of bronchopulmonary dysplasia. In this group of extremely immature infants, we found that the
Table 6 Results of adjusted binary logistic regression analysis for main outcomes in the second study period (2016-2017) as compared with the first study period (2012-2013) in patients born with less than 29 weeks gestational age. Adjusted for perinatal risk factors: gestational age, gender, antenatal steroids, and placental histology. $S F-B P D$, survival without BPD grades 2-3; $M V$, mechanical ventilation; $H F O V$, highfrequency oscillatory ventilation; $S F$, survival without

\begin{tabular}{|c|c|c|c|}
\hline 2016-2017 vs 2012-2013 in less than 29 wGA ( $n$ 139) & OR & $95 \%$ IC & $p$ value \\
\hline SF-BPD in patients exposed to MV in the first $3 \mathrm{dol}$ & 4.869 & $1.900-12.478$ & 0.001 \\
\hline SF-BPD in infants exposed to MV after the first 3 dol & 1.455 & $0.452-4.689$ & 0.530 \\
\hline SF-BPD in infants not exposed to MV during hospitalization & 1.059 & $0.947-1.184$ & 0.400 \\
\hline SF-BPD in patients in VAFO at $3 \mathrm{dol}$ & 9.247 & $1.487-53.889$ & 0.013 \\
\hline SF-pathologic cranial ultrasound & 0.831 & $0.393-1.756$ & 0.627 \\
\hline DBP $2-3$ in survivors & 0.201 & $0.073-0.559$ & 0.002 \\
\hline
\end{tabular}


modifications to the HFOV management strategy were associated with at least a $48 \%$ increase in SF-BPD (Table 6).

Although our results have been adjusted for perinatal risk factors, it should be borne in mind that the earlier use of HFOV in the new strategy period may have given rise to more severe respiratory distress syndrome in patients treated using this method at 3 days old in the baseline period. What we can infer with more certainty is that the combination of these two strategies, the earlier use of HFOV together with a reduced VThf and higher frequencies, is associated with an increase in SF-BPD.

There is increasing evidence that pulmonary overdistension secondary to the use of high tidal volumes is the determining factor in VILI and therefore a pathogenic factor in the development of bronchopulmonary dysplasia $[53,54]$. Alveolar overdistension is often due to heterogeneous pulmonary recruitment where, despite a relatively low tidal volume, said volume is only distributed over the recruited areas, producing overdistension in these zones while the rest of the lung remains atelectatic. This is why it is so important to achieve optimal pulmonary recruitment, with HFOV being the most suitable ventilator mode because it allows for standardized recruitment maneuvers with minimum pressure changes over the respiratory cycle, thus maintaining a constant lung volume $[55,56]$.

Therefore, although the best protection against VILI is to avoid intubation by employing noninvasive strategies [57, 58], we believe that HFOV applied at high frequencies and with a low VThf can currently be considered the best way to protect against lung damage in preterm infants who need to be connected to a ventilator.

The main limitation of this study is that it is observational and the patients have been compared from two different time periods. As such, some other differences that occurred between these periods could have influenced the results. In fact, the surfactant administration technique was modified and noninvasive ventilation was used more frequently in the second period with the new strategy which meant that the subjects in each period had different baseline characteristics. Also, VG on HFOV was only employed in the second period, and it could also have had an impact on BPD reduction. To the best of our knowledge, only one small study has analyzed the long-term impact of HFOV combined with $\mathrm{VG}$, and the authors observed a reduction in the combined outcome of death or BPD [51]. But it should be noted that the VG group in this study had a higher gestational age and there were fewer patients. We believe that VG enables greater tidal volume stability and facilitates management on HFOV, yet the lower incidence of DBP observed in the present study cannot be attributed solely to the implementation of VG, but also to the combination of all lung protective strategies.
Another aspect to consider is the multifactorial origin of this pathology and that in this study only assessed VILI, so we cannot rule out the interaction of other factors even though all outcomes were adjusted for potential confounders.

Another noteworthy point is that this is a single-center study, in which the only ventilator used in HFOV+VG mode was the Babylog® VN500, so VThf values may differ from those required when using another device.

In conclusion, we found that the early use of HFOV with a very low VThf and at very high frequencies was associated with a reduced incidence of grade $2-3$ bronchopulmonary dysplasia in our population, particularly in higher risk patients such as those with a gestational age of less than 29 weeks.

Authors' contribution Cristina Ramos Navarro designed the study, performed the acquisition and analysis of the data, and drafted the test. Noelia González Pacheco and Ana Rodríguez Sánchez de la Blanca collected data during the study period. Manuel Sánchez Luna made contributions on the conception of the work and revised the draft critically. All the authors revised and approved the final version of the text.

\section{Compliance with ethical standards}

Conflict of interest Sánchez-Luna. $\mathrm{M}$ has received advisory board consulting fees from Dräger. The remaining authors have no conflicts to declare.

Ethical approval This article does not contain any studies with human participants or animals performed by any of the authors. This study was approved and monitored by the Clinical Research Ethics Committee at Gregorio Marañón Hospital (07/17). ClinicalTrials.gov Identifier: NCT03411018

\section{References}

1. Sweet DG, Carnielli V, Greisen G, Hallman M, Ozek E, Plavka R et al (2017) European consensus guidelines on the management of respiratory distress syndrome - 2016 update. Neonatology. 111(2): $107-125$

2. Jobe AH (2015) Animal models, learning lessons to prevent and treat neonatal chronic lung disease. Frontiers in Medicine 2:49

3. Caskey S, Gough A, Rowan S, Gillespie S, Clarke J, Riley M et al (2016) Structural and functional lung impairment in adult survivors of bronchopulmonary dysplasia. Ann Am Thorac Soc 13(8):12621270

4. McGrath-Morrow SA, Collaco JM (2019) Bronchopulmonary dysplasia: what are its links to COPD? Therapeutic advances in respiratory disease $; 13: 1753466619892492$.

5. Hernandez LA, Peevy KJ, Moise AA, Parker JC (1989) Chest wall restriction limits high airway pressure-induced lung injury in young rabbits. J Appl Physiol 66(5):2364-2368

6. Carlton DP, Cummings JJ, Scheerer RG, Poulain FR, Bland RD (1990) Lung overexpansion increases pulmonary microvascular protein permeability in young lambs. J Appl Physiol 69(2):577-583

7. Kalikkot Thekkeveedu R, Guaman MC, Shivanna B (2017) Bronchopulmonary dysplasia: a review of pathogenesis and pathophysiology. Respir Med 132:170-177

8. Sweet DG, Carnielli V, Greisen G, Hallman M, Ozek E, Te Pas A et al (2019) European consensus guidelines on the management of 
respiratory distress syndrome - 2019 update. Neonatology. 115(4): $432-451$

9. McCulloch PR, Forkert PG, Froese AB (1988) Lung volume maintenance prevents lung injury during high frequency oscillatory ventilation in surfactant-deficient rabbits. Am Rev Respir Dis 137(5): $1185-1192$

10. Cools F, Offringa M, Askie LM (2015) Elective high frequency oscillatory ventilation versus conventional ventilation for acute pulmonary dysfunction in preterm infants. Cochrane Database Syst Rev 3:CD000104

11. Rieke H, Hook C, Meyer M (1983) Pulmonary gas exchange during high-frequency ventilation in dogs. Respir Physiol 54(1):1-17

12. Watson JW, Jackson AC, Gillespie JR (1984) CO2 elimination and airway opening pressure during high frequency oscillation in dogs. Respir Physiol 58(2):235-244

13. Sedeek KA, Takeuchi M, Suchodolski K, Kacmarek RM (2003) Determinants of tidal volume during high-frequency oscillation. Crit Care Med 31(1):227-231

14. Slutsky AS, Drazen FM, Ingram RH Jr, Kamm RD, Shapiro AH, Fredberg JJ et al (1980) Effective pulmonary ventilation with smallvolume oscillations at high frequency. Science. 209(4456):609671

15. Boynton BR, Hammond MD, Fredberg JJ, Buckley BG, Villanueva D, Frantz ID 3rd. (1989) Gas exchange in healthy rabbits during high-frequency oscillatory ventilation. J Appl Physiol 66(3):1343-1351

16. R S. High-frequency ventilation - basics and practical applications. Lübeck, Germany: Drägerwerk AG; 1995.

17. Sanchez Luna M, Santos Gonzalez M, Tendillo CF (2013) Highfrequency oscillatory ventilation combined with volume guarantee in a neonatal animal model of respiratory distress syndrome. Crit Care Res Pract 2013:593915

18. Mukerji A, Belik J, Sanchez-Luna M (2014) Bringing back the old: time to reevaluate the high-frequency ventilation strategy. $\mathrm{J}$ Perinatol: official journal of the California Perinatal Association 34(6):464-467

19. Belteki G, Morley CJ (2019) High-frequency oscillatory ventilation with volume guarantee: a single-centre experience. Arch Dis Child Fetal Neonatal Ed 104(4):F384-F3F9

20. Pillow JJ, Sly PD, Hantos Z, Bates JH (2002) Dependence of intrapulmonary pressure amplitudes on respiratory mechanics during high-frequency oscillatory ventilation in preterm lambs. Pediatr Res 52(4):538-544

21. Venegas JG, Fredberg JJ (1994) Understanding the pressure cost of ventilation: why does high-frequency ventilation work? Crit Care Med 22(9 Suppl):S49-S57

22. Sanchez-Luna M, Gonzalez-Pacheco N, Belik J, Santos M, Tendillo F (2018) New ventilator strategies: high-frequency oscillatory ventilation combined with volume guarantee. Am J Perinatol 35(6):545-548

23. Dorkin HL, Stark AR, Werthammer JW, Strieder DJ, Fredberg JJ, Frantz ID (1983) Respiratory system impedance from 4 to $40 \mathrm{~Hz}$ in paralyzed intubated infants with respiratory disease. J Clin Invest 72(3):903-910

24. Pillow JJ (2005) High-frequency oscillatory ventilation: mechanisms of gas exchange and lung mechanics. Crit Care Med 33(3 Suppl):S135-S141

25. Abad-Garcia MF, Gonzalez-Teruel A, Solis SG (2016) Contribution of Anales de Pediatria to the international visibility of Spanish paediatric research in the Web of Science (2010-2014). An Pediatr (Barc) 85(6):305-311

26. González-Pacheco N, Sánchez-Luna M, Arribas-Sánchez C, Santos-González M, Orden-Quinto C, Tendillo-Cortijo F. DCO. Eur J Pediatr. 2020;179(3):499-506.
27. Froese AB, Kinsella JP (2005) High-frequency oscillatory ventilation: lessons from the neonatal/pediatric experience. Crit Care Med 33(3 Suppl):S115-S121

28. Lee S, Alexander J, Blowes R, Ingram D, Milner AD (1999) Determination of resonance frequency of the respiratory system in respiratory distress syndrome. Arch Dis Child Fetal Neonatal Ed 80(3):F198-F202

29. Gonzalez-Pacheco N, Sanchez-Luna M, Chimenti-Camacho P, Santos-Gonzalez M, Palau-Concejo P, Tendillo-Cortijo F (2019) Use of very low tidal volumes during high-frequency ventilation reduces ventilator lung injury. J Perinatol: official journal of the California Perinatal Association

30. Gonzalez-Pacheco N, Sanchez-Luna M, Ramos-Navarro C, Navarro-Patino N, de la Blanca AR (2016) Using very high frequencies with very low lung volumes during high-frequency oscillatory ventilation to protect the immature lung. A pilot study. J Perinatol: official journal of the California Perinatal Association 36(4):306-310

31. Ramos-Navarro C, Sanchez-Luna M, Sanz-Lopez E, MaderueloRodriguez E, Zamora-Flores E (2016) Effectiveness of synchronized noninvasive ventilation to prevent intubation in preterm infants. AJP reports 6(3):e264-e271

32. Ramos-Navarro C, Sanchez-Luna M, Zeballos-Sarrato S, Gonzalez-Pacheco N (2016) Less invasive beractant administration in preterm infants: a pilot study. Clinics. 71(3):128-134

33. De Luca D, Minucci A, Gentile L, Capoluongo ED (2014) Surfactant inadvertent loss using feeding catheters or endotracheal tubes. Am J Perinatol 31(3):209-212

34. Lemyre B, Laughon M, Bose C, Davis PG (2016) Early nasal intermittent positive pressure ventilation (NIPPV) versus early nasal continuous positive airway pressure (NCPAP) for preterm infants. Cochrane Database Syst Rev 12:Cd005384

35. De Luca D, Shankar-Aguilera S, Centorrino R, Fortas F, Yousef N, Carnielli VP (2020) Less invasive surfactant administration: a word of caution. Lancet Child Adolesc Health

36. Redline RW, Boyd T, Campbell V, Hyde S, Kaplan C, Khong TY et al (2004) Maternal vascular underperfusion: nosology and reproducibility of placental reaction patterns. Pediatr Dev Pathol 7(3): 237-249

37. Redline RW (2015) Classification of placental lesions. Am J Obstet Gynecol 213(4 Suppl):S21-S28

38. The CRIB (1993) (clinical risk index for babies) score: a tool for assessing initial neonatal risk and comparing performance of neonatal intensive care units. The International Neonatal Network. Lancet. 342(8865):193-198

39. Jobe AH, Bancalari E (2001) Bronchopulmonary dysplasia. Am J Respir Crit Care Med 163(7):1723-1729

40. Walsh MC, Yao Q, Gettner P, Hale E, Collins M, Hensman A et al (2004) Impact of a physiologic definition on bronchopulmonary dysplasia rates. Pediatrics. 114(5):1305-1311

41. Townsel CD, Emmer SF, Campbell WA, Hussain N (2017) Gender differences in respiratory morbidity and mortality of preterm neonates. Front Pediatr 5:6

42. Stoll BJ, Hansen NI, Bell EF, Walsh MC, Carlo WA, Shankaran S et al (2015) Trends in care practices, morbidity, and mortality of extremely preterm neonates, 1993-2012. Jama. 314(10):1039-1051

43. Roberts D, Brown J, Medley N, Dalziel SR (2017) Antenatal corticosteroids for accelerating fetal lung maturation for women at risk of preterm birth. Cochrane Database Syst Rev 3:Cd004454

44. Çakir U, Yildiz D, Kahvecioğlu D, Okulu E, Alan S, Erdeve Ö et al (2019) Placenta, secret witness of infant morbidities: the relationship between placental histology and outcome of the premature infant. Turk Patoloji Derg 35(1):28-35

45. Pillow JJ (2012) Tidal volume, recruitment and compliance in HFOV: same principles, different frequency. Eur Respir J 40(2): 291-293 
46. van Kaam AH, De Luca D, Hentschel R, Hutten J, Sindelar R (2019) Thome U, et al. Modes and strategies for providing conventional mechanical ventilation in neonates, Pediatr Res

47. Zannin E, Dellaca' RL, Dognini G, Marconi L, Perego M, Pillow JJ et al (2017) Effect of frequency on pressure cost of ventilation and gas exchange in newborns receiving high-frequency oscillatory ventilation. Pediatr Res 82(6):994-999

48. Kneyber MC, van Heerde M, Markhorst DG (2012) Reflections on pediatric high-frequency oscillatory ventilation from a physiologic perspective. Respir Care 57(9):1496-1504

49. Kneyber MC, Markhorst DG (2016) Do we really know how to use high-frequency oscillatory ventilation in critically ill children? Am J Respir Crit Care Med 193(9):1067-1068

50. Iscan B, Duman N, Tuzun F, Kumral A, Ozkan H (2015) Impact of volume guarantee on high-frequency oscillatory ventilation in preterm infants: a randomized crossover clinical trial. Neonatology. 108(4):277-282

51. Chen LJ, Chen JY (2019) Effect of high-frequency oscillatory ventilation combined with volume guarantee on preterm infants with hypoxic respiratory failure. Crit Care Med 82(11):861-864

52. Enomoto M, Keszler M, Sakuma M, Kikuchi S, Katayama Y, Takei A et al (2017) Effect of volume guarantee in preterm infants on high-frequency oscillatory ventilation: a pilot study. Am J Perinatol 34(1):26-30
53. Slutsky AS (2005) Ventilator-induced lung injury: from barotrauma to biotrauma. Respir Care 50(5):646-659

54. Slutsky AS, Ranieri VM (2013) Ventilator-induced lung injury. N Engl J Med 369(22):2126-2136

55. Berger TM, Fontana M, Stocker M (2013) The journey towards lung protective respiratory support in preterm neonates. Neonatology. 104(4):265-274

56. De Jaegere A, van Veenendaal MB, Michiels A, van Kaam AH (2006) Lung recruitment using oxygenation during open lung high-frequency ventilation in preterm infants. Am J Respir Crit Care Med 174(6):639-645

57. Fischer HS, Buhrer C (2013) Avoiding endotracheal ventilation to prevent bronchopulmonary dysplasia: a meta-analysis. Pediatrics. 132(5):e1351-e1360

58. Schmölzer GM, Kumar M, Pichler G, Aziz K, O’Reilly M, Cheung PY (2013) Non-invasive versus invasive respiratory support in preterm infants at birth: systematic review and meta-analysis. BMJ. 347:f5980

Publisher's note Springer Nature remains neutral with regard to jurisdictional claims in published maps and institutional affiliations. 